\title{
Structural Behaviour and Design of Geopolymer Concrete Members
}

\author{
Sarker, P.K. ${ }^{1}$
}

\begin{abstract}
The worldwide production of concrete is on the increase in order to meet the increasing rate of construction. Since cement production contributes to the greenhouse gas emission, it is vital to develop alternative low-emission binders to reduce the carbon footprint of concrete. Fly ash based geopolymer is an alternative binder that has potential to reduce the $\mathrm{CO}_{2}$ emission of concrete production. It has been shown in different studies that the mechanical properties of geopolymer concrete are comparable to those of ordinary Portland cement (OPC) concrete. This paper describes the behaviour and design aspects of geopolymer concrete structural members. The design aspects presented in this paper are bond of reinforcing steel in pullout and spliced bars in beams, beams in shear and flexure, and columns in uniaxial and biaxial bending. It is shown that the current provisions for OPC concrete can be conservatively used for design of reinforced geopolymer concrete members.
\end{abstract}

Keywords: Fly ash; geopolymer; reinforced concrete; structural design.

\section{Introduction}

Concrete is the most commonly used construction material in the world. Ordinary Portland cement (OPC) has been traditionally used as the binding agent for manufacturing concrete. The worldwide cement production in the year 2014 was estimated as 4.3 billion tonnes [1] that is increasing every year in order to meet the increasing demand for infrastructures. About 1 tonne of carbon dioxide is released to the atmosphere in the manufacturing process of 1 tonne of cement [2]. Cement production contributes about $5 \%$ to $7 \%$ carbon dioxide gas emission of the world [3]. The use of alternative low-emission binders in concrete is an effective way to reduce environmental impact of concrete production. Geopolymer is an alternative binder that uses by-product materials instead of cement. The fly ash based geopolymer binder uses fly ash, which is an industrial by-product from coal-fired power stations. Large amount of fly ash is generated globally every year by the coal-fired power stations. The generation of fly ash is increasing to meet the increasing demand of electricity in some countries such as India [4]. This is because of the huge reserve of good quality coals and the higher cost effectiveness of using coal for generation of electricity as compared to some other renewable sources such as solar panels and wind turbines. Substantial quantity of this fly ash remains unused in many countries. The disposal or storage of the unused fly ash occupies a substantial acreage of land that could be used for other productive purposes. Thus, the increasing reserve of under-utilised fly ash can be used to produce geopolymer concrete and reduce the carbon footprint of concrete production.

${ }^{1}$ Department of Civil Engineering, Curtin University, Perth, WA 6102, AUSTRALIA . E-mail: p.sarker@curtin.edu.au
Geopolymer is a type of inorganic polymer that shows good bonding properties. An alumino-silicate source material such as fly ash or metakaolin is reacted with an alkali to produce the geopolymer binder. The properties of geopolymer binder vary depending on the ratio of $\mathrm{Si}$ to $\mathrm{Al}$ in the reaction product [5]. The geopolymer binds the conventional coarse and fine aggregates to produce concrete. Sodium hydroxide and sodium silicate are some common type of alkalis used to make the geopolymer binder for concrete applications. Water and superplasticizer may be added to improve workability of the concrete. Recent studies on heat cured geopolymer concrete have shown its potential use as a construction material [6-9]. Heat-cured fly ash geopolymer concrete has the properties of high compressive strength, very little drying shrinkage, low creep, and good resistance to acid and sulphate attack. These are some desirable properties of concrete for its application as a structural material. Other recent studies [10-12] have shown that addition of small quantity of calcium bearing compounds such as blast furnace slag or cement can improve the setting and strength development at room temperature. Thus, geopolymer concrete mixtures can be designed to achieve desired setting times and normal compressive strengths for general applications without curing at elevated temperatures.

Since geopolymer concrete is a relatively new construction material, it is essential to understand its various structural behaviours in order to use it with confidence. It is important to understand the response to load and failure behaviour of members such as beams and columns in order to use it in reinforced concrete structures. Studies on the structural behavior of reinforced geopolymer concrete are scarce in literature. The flexural behaviour of reinforced geo- 
polymer concrete beams was studied by Sumajouw et al. [13]. This paper describes the bond behaviour of geopolymer concrete with reinforcing steel, shear strength of geopolymer concrete beams, and strength and deflection of geopolymer concrete columns.

\section{Materials}

Low-calcium Class F fly ash was used as the base material to produce geopolymer concrete. Conventional crushed granite and sand were used as the coarse and fine aggregates. The aggregates were prepared to saturated-surface-dry (SSD) condition before mixing the concrete. The alkaline liquid was a combination of sodium hydroxide and sodium silicate solutions. The sodium hydroxide solution was made by dissolving commercial grade $\mathrm{Na}(\mathrm{OH})$ solids in tap water. The chemical composition of the commercial grade sodium silicate solution was $14.7 \% \mathrm{Na}_{2} \mathrm{O}$, $29.4 \% \mathrm{SiO}_{2}$, and $55.9 \%$ water by mass. A comercially available naphthalene sulphonated super plasticizer was added to improve the workability of fresh geopolymer concrete. Effects of various mixture design parameters on the properties of geopolymer concrete were comprehensively studied by Hardjito and Rangan [14]. The geopolymer concrete mixture proportions used to cast the test specimens described in the following sections were based on those of Reference 13. Strength of geopolymer concrete usually increases with the increase in molarity of the alkaline liquid, curing temperature and curing time $[8,14]$. An increase in the water to solids ratio usually improves workability of the mixture but reduces the strength of geopolymer concrete. The test specimens of the experimental programs were cast by using freshly mixed geopolymer concrete in the laboratory and were steam-cured at $60{ }^{\circ} \mathrm{C}$ for 24 hours. The reinforcing steel bars used in the specimens were Australian $500 \mathrm{MPa}$ hot rolled deformed bars.

\section{Structural Behaviour and Design of Geo- polymer Concrete Members}

\section{Bond Strength with Reinforcing Steel}

The knowledge of bond behaviour between reinforcing steel and concrete is critical to the design of reinforced concrete structures. Bond behaviour is the interaction of the reinforcing bar with the concrete. This is described as the transfer of forces from the reinforcement to the surrounding concrete by adhesion between the bar and concrete, frictional force at the interface and bearing of the ribs of deformed bars against the concrete. The adhesion depends on the bar surface condition and the type of concrete. Bond resistance is governed by several factors such as compressive and tensile strengths of concrete, the concrete cover to the bar, confinement due to transverse reinforcement, surface condition of the bar and bar geometry [15]. The design provisions of reinforced concrete as a composite material utilize the bond strength between the two materials. The commonly used steel reinforcing bars have been developed for use with OPC concrete. The bond strength of fly ash-based geopolymer concrete with reinforcing steel was investigated by using direct pull-out tests of beam-end specimens and lap splicing of bars in beams in bending.

Twenty four geopolymer and 24 OPC concrete beamend specimens were manufactured and tested for pull out in accordance with the ASTM 944 Standard [16] to study the bond between concrete and reinforcing bars [17]. The geometry of the specimens is shown in Figure 1. The test parameters were bar diameter, concrete cover to the pull-out bar and concrete compressive strength. The bar diameter $\left(d_{b}\right)$ was either $20 \mathrm{~mm}$ or $24 \mathrm{~mm}$. The compressive strength $\left(f_{c}\right)$ of geopolymer concrete varied between 25 and $39 \mathrm{MPa}$. The concrete cover to bar diameter ratio $\left(c / d_{b}\right)$ varied from 1.71 to 3.40 .

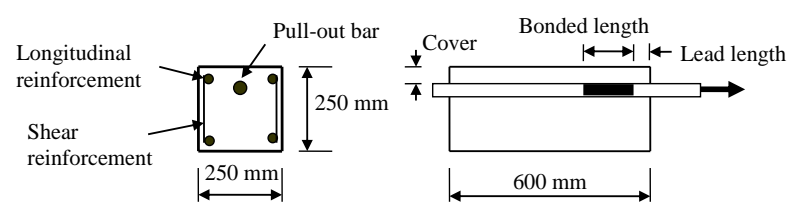

Figure 1. Beam-end Specimens for Pull-out Tests

Failure occurred in a brittle manner by splitting of the concrete cover in both geopolymer and OPC concrete specimens, as shown in Figures 2(a) and 2(b). Effect of the design parameters on the bond strength of both types of concrete in these specimens are summarized in Figure 3. The normalized bond strength $(u)$ with respect to the square root of concrete compressive strength $\left(f e^{0.5}\right)$ is plotted against the concrete cover to bar diameter ratio $(c / d b)$. It is seen from the figure that the trend line for geopolymer concrete is above that for OPC concrete. This indicates that geopolymer concrete has higher normalized bond strength than OPC concrete for the same design parameter. The higher bond strength of geopolymer is attributed to its higher splitting tensile strength than OPC concrete of the same compressive strength. A comparison based on comprehensive experimental data shows that heat-cured fly ash geopolymer concrete has higher tensile strength than OPC concrete of the same compressive strength [18].

The bond strength of geopolymer concrete with reinforcing steel bars was also studied by using lap spliced bars in beam specimens under bending moment [19]. Twelve beams of $200 \mathrm{~mm} \times 300 \mathrm{~mm}$ in cross section and $2500 \mathrm{~mm}$ in length were tested in the laboratory. Concrete compressive strength 
ranged from 29 to $55 \mathrm{MPa}$. The reinforcement configuration of the test beams is shown in Figure 4. The beams were tested in simply supported conditions subjected to pure bending moment in the spliced region. All the beams failed by splitting of the concrete in the spliced region, as shown in Figure 5. This failure type in the geopolymer concrete specimens is similar to the type of bond failure usually observed in OPC concrete beams. The current code provisions of the Australian Standard AS 3600 [20] and the American Concrete Institute Code ACI 318 [21] to calculate the bond strength of OPC concrete beams were used to calculate the bond strengths of the geopolymer concrete test beams. The results of the analysis showed that both the codes provided with conservative predictions of the bond strength of the test beams. The mean values of the test to predicted bond strength ratio for the 12 test beams were 2.03 and 1.70 by the AS3600 and ACI 318 codes, respectively. This shows that the current design codes can be used for conservative design of the bond strength of geopolymer concrete with reinforcing steel bars.

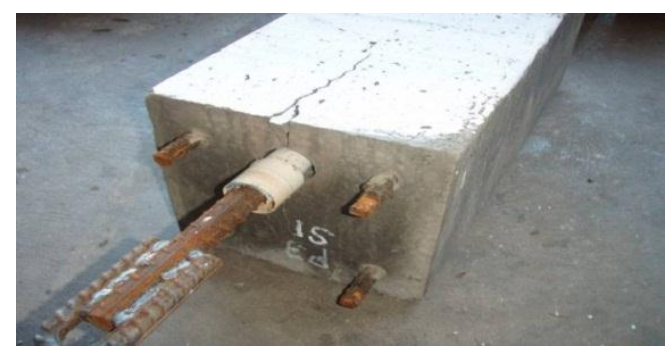

Figure 2(a). Failure of Geopolymer Concrete Specimen

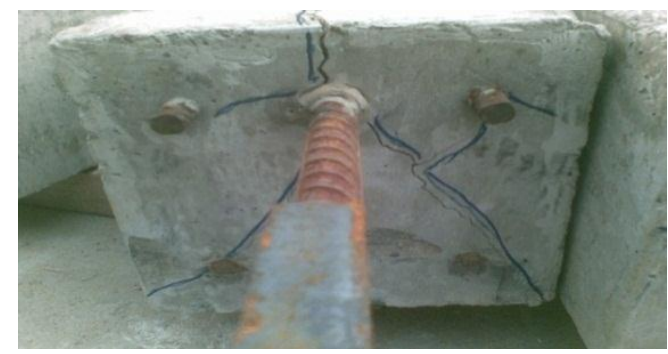

Figure 2(b). Failure of OPC Concrete Specimen

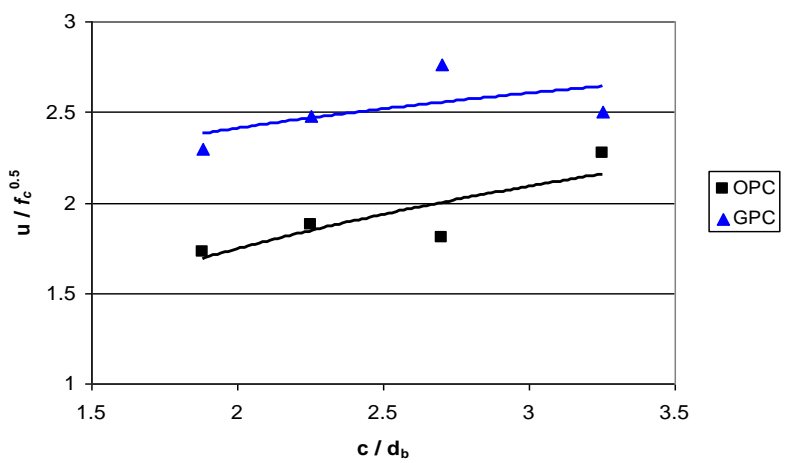

Figure 3. Comparison of the Bond Strengths of Geopolymer and OPC Concretes in Pull-out Tests

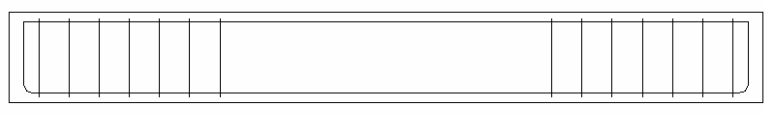

Elevation

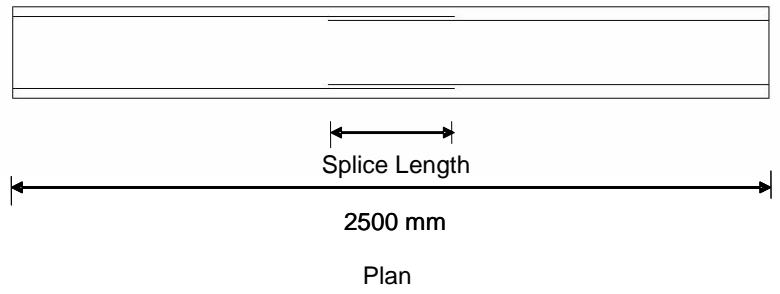

Figure 4. Lap Splicing of Reinforcing Bars in Beams for Bond Test

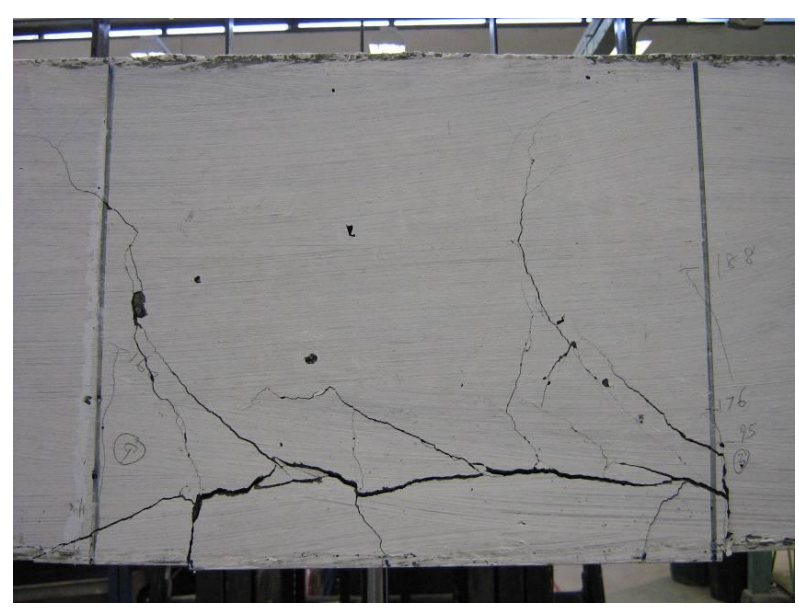

Figure 5. Splitting Failure of Geopolymer Concrete in the Splice Region

\section{Strength of beams in shear and flexure}

Nine geopolymer concrete beams were cast and tested in the laboratory in order to study the shear behaviour of geopolymer concrete beams [22]. The beams were $200 \mathrm{~mm} \times 300 \mathrm{~mm}$ in cross section and $2000 \mathrm{~mm}$ in length. The concrete compressive strength varied between $44 \mathrm{MPa}$ to $56 \mathrm{MPa}$. The longitudinal tensile reinforcement ratio ranged from 1.74 to 3.14 and the shear reinforcement ratio varied between 0.10 and 0.17 . The reinforcement configuration in a typical test beam is shown in Figure 6 . The beams were tested for a shear span to depth ratio of 2.5. A typical failure of the reinforced geopolymer concrete beams in shear is shown in Figure 7. The observed failure type is typical of that shown by OPC concrete beams in shear. The failure occured suddenly that is generally expected in shear critical concrete beams. The ultimate shear load was calculated by using the Australian standard (AS 3600) and compared to that measured in the tests. The shear strengths of the test beams calculated by the Australian Standard were conservative predictions of the ultimate shear strengths of the beams. The mean value of the ratios of test to predicted ultimate shear loads for the nine geopolymer con- 
crete test beams was 1.60 with a standard deviation of 0.24 .

Use of the Australian Standard (AS 3600) was also found to result in conservative design of geopolymer concrete beams for flexural load, as shown by Sumajouw et al. [13]. Thus, the results of the experimental and analytical studies on flexure and shear behaviour show that geopolymer concrete beams can be designed conservatively using the current Australian Standard for OPC concrete.

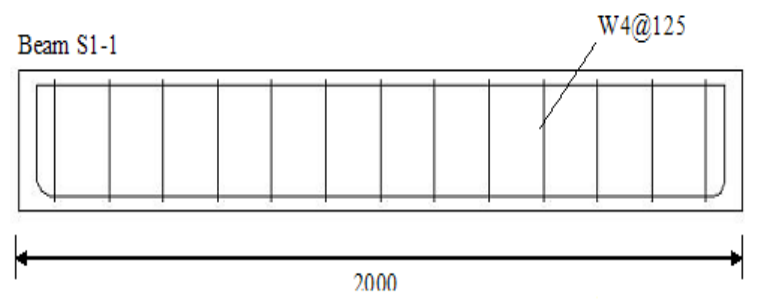

Figure 6. Reinforcement in a Shear Test Specimen

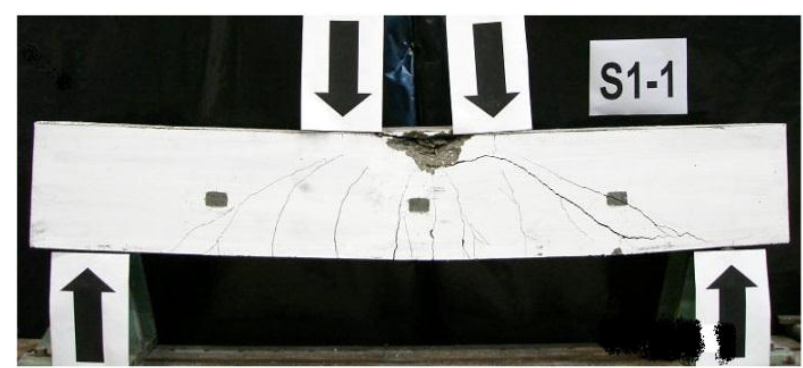

Figure 7. Failure of a Geopolymer Concrete Beam in Shear Test

\section{Columns in Compression at Uniaxial Load Eccentricity}

Twelve geopolymer concrete slender columns were tested by Sumajouw et al. for axial load combined with uniaxial bending [23]. The concrete compressive strength of the test columns varied between $42 \mathrm{MPa}$ and $66 \mathrm{MPa}$. The columns were $175 \mathrm{~mm} \times 175 \mathrm{~mm}$ in cross section and $1500 \mathrm{~mm}$ in length. The longitudinal reinforcement ratio of the columns was either $1.44 \%$ or $2.88 \%$. The load eccentricity to column depth ratio varied from 0.09 to 0.29 . It was observed that the failure behaviour of the geopolymer concrete columns was similar to that of OPC concrete columns. Analysis of the columns by using the AS 3600 Standard and ACI 318 Code resulted in conservative predictions of the failure loads [23].

Later, a stress-strain relationship was modified for geopolymer concrete and it was incorporated in a nonlinear finite difference method of column analysis developed by the author [24]. The analytical procedure was used to calculate the ultimate strength and load-deflection behaviour of the test columns. The mean value of the ratios of test to calculated failure loads by using the analytical method was 1.03 with a standard deviation of 0.05 . Comparisons of the typical experimental and calculated load-deflection curves are shown in Figure 8. It can be seen from the figure that the calculated load-deflection curves correlated well with the experimentally measured load-deflection curves. Thus, the existing codes and analytical methods used for OPC concrete columns can be used for conservative prediction of the strength of geopolymer concrete slender columns under eccentric loading. Also, the load-deflection behaviour of slender geopolymer concrete columns can be predicted by using the analytical approaches commonly used for OPC concrete columns.

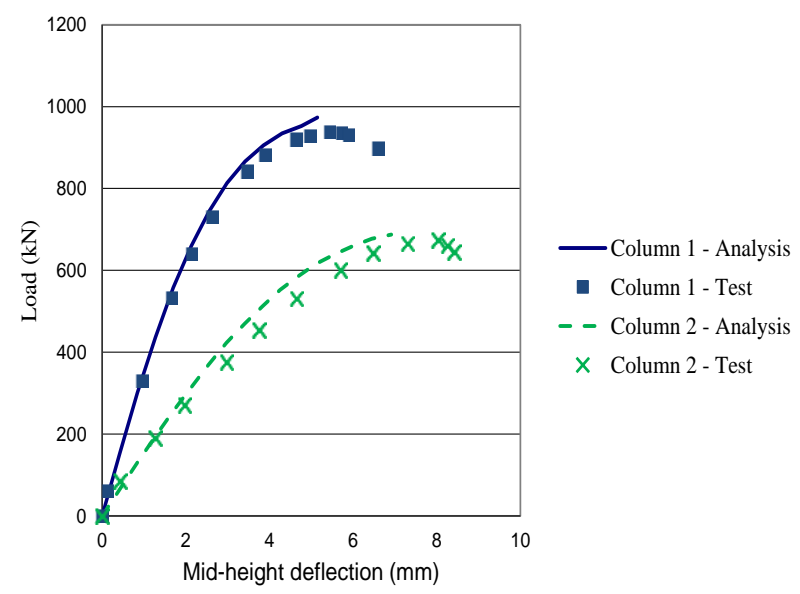

Figure 8. Load-deflection Curves of Geopolymer Concrete Columns

\section{Columns in Compression at Biaxial Load Eccentricities}

Reinforced concrete columns subjected to axial compression and biaxial bending are common in structures such as buildings and bridges. Twelve geopolymer concrete columns were tested in biaxial load eccentricities to understand the behaviour of the columns under combined axial compression and biaxial bending [25]. The columns were $175 \mathrm{~mm} \times$ $175 \mathrm{~mm}$ in cross section and $1500 \mathrm{~mm}$ in length. The columns were cured by steam for 24 hours at $60{ }^{\circ} \mathrm{C}$ and then left in outdoor environment until testing. The specimens were exposed to normal variations of the winter and summer weather conditions during this period. The cylinder compressive strength during testing of the columns varied between $37 \mathrm{MPa}$ and $63 \mathrm{MPa}$. The longitudinal reinforcement consisted of $500 \mathrm{MPa}$ N12 (diameter, $12 \mathrm{~mm}$ ) deformed bars and the lateral ties were made of $6 \mathrm{~mm}$ diameter wires. The longitudinal reinforcement ratio was either $1.47 \%$ or $2.95 \%$ with 4 or 8 bars, respectively. 
The columns were tested by using specially made knife-edge assemblages at both ends to achieve the required load eccentricities simultaneously about both the principal axes. The test setup and the knifeedge assemblages are shown in Figure 9. The knifeedges were adjusted to achieve load eccentricities from $15 \mathrm{~mm}$ to 70 in the $\mathrm{X}$ and $\mathrm{Y}$ directions. The columns were tested with a wide range of ratios between the load eccentricities. The ratio of the load eccentricities ( $\mathrm{e}_{\mathrm{y}} / \mathrm{e}_{\mathrm{x}}$ ) varied between 0.71 and 3.33. The load eccentricity to depth ratio (ex/D) varied between 0.09 and 0.40 .

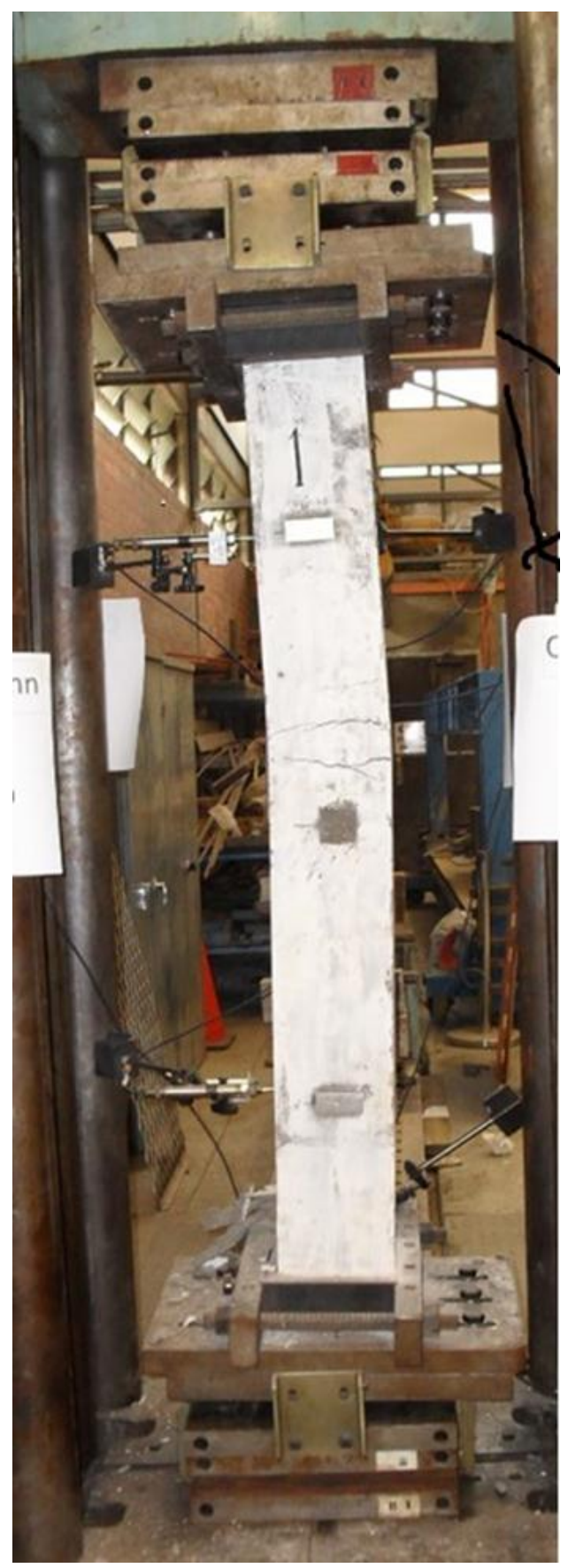

Figure 9. Test of Geopolymer Concrete Column in Combined Axial Compression and Biaxial Bending
Figure 9 shows the typical failure of a geopolymer concrete column in compression and biaxial bending. A typical failure was characterized by spalling and crushing of the concrete in compression zone and widening of the cracks in the tension faces. Usually cracks initiated on the tension faces at mid height of the columns as the loading progressed. The existing cracks propagated and new cracks initiated with the increase of load. The cracks near the mid-height opened widely before the failure. The failure zone was in the vicinity of the mid height for all columns. Buckling of longitudinal reinforcing bars was observed after spalling of the concrete from the compression zone. The failure was more brittle with shorter post-peak load-deflection curves for the columns with smaller load eccentricity and higher concrete compressive strength. As expected, generally the mid-height deflection increased with the increase of load eccentricity. Generally, the loaddeflection and the failure behaviour of geopolymer concrete columns under biaxial bending were similar to those exhibited by OPC concrete columns previously tested using the same test set up [26]. The failure load of the columns varied between $392 \mathrm{kN}$ and $1377 \mathrm{kN}$ depending on the concrete compressive strength, longitudinal reinforcement ratio and the biaxial load eccentricities. As usually shown by OPC concrete columns, the failure loads increased with the increase of concrete compressive strength and the longitudinal reinforcement ratio, and decreased with the increase in load eccentricities.

The failure loads of the test columns were calculated by using the well-known Bresler's reciprocal load formula [27]. The reciprocal formula (Equation 1) is simple and easy to use.

$\frac{1}{P}=\frac{1}{P_{x}}+\frac{1}{P_{y}}-\frac{1}{P_{0}}$

where, $P$ is the strength of the column in biaxial bending, $P_{x}$ and $P_{y}$ are the strengths at uniaxial load eccentricities of $e_{y}$ and $e_{x}$ respectively, and $P_{0}$ is the strength under pure axial compression.

The pure axial load capacity of the column is calculated by using Equation 2.

$P_{0}=0.85 f_{c m}\left(A_{g}-A_{s}\right)+f_{y} A_{s}$

where, $f_{c m}$ is the mean cylinder compressive strength, $A_{g}$ is the gross cross sectional area, $A_{s}$ is the area of reinforcing steel and $f_{y}$ is the yield strength of steel.

Calculations of $P_{x}$ and $P_{y}$ were performed by an iterative procedure of calculating the load-moment interaction relationships using a spreadsheet program. The moment capacity of the cross-section was 
calculated by using the rectangular stress block parameters of the Australian Standard AS 3600 [20]. Calculation of the maximum bending moment of the column was based on the load eccentricity, slenderness ratio and mid-height deflection. The midheight deflections in $X$ and $Y$ directions were calculated by using the method recommended by Rangan for slender reinforced concrete columns [28]. Thus, the method has taken into account the second order effect of slender columns in the calculation of the column strength in uniaxial bending. The value of the axial load for which the mid-height bending moment in the column reached the moment capacity of the cross-section was taken as the ultimate load capacity for uniaxial bending.

The load capacity of the test columns in biaxial bending were calculated by using Equation 1 and compared with the values obtained in the tests. The mean ratio of the test to calculated failure loads of the 12 test columns was 1.18 with a standard deviation of 0.15 . The ratio was found to be relatively higher for the columns with smaller load eccentricities than for the columns with larger load eccentricities. Generally it was shown that the Bresler's reciprocal formula can be conservatively used for prediction of the strength of geopolymer concrete columns in biaxial bending.

\section{Concluding Remarks}

Structural behaviour of reinforced fly ash based geopolymer concrete members has been presented. The pull-out test results on beam-end specimens showed that geopolymer concrete has higher bond strength than OPC concrete for the same test parameters. The higher bond strength of geopolymer concrete is attributed to its higher splitting tensile strength than OPC concrete of the same compressive strength. The failure behaviour of geopolymer concrete beams with lap spliced reinforcement was similar to that of OPC concrete beams. The current design codes such as the Australian Standard and ACI code are conservative for designing the anchorage length of reinforcing steel embedded in geopolymer concrete. These methods are also conservative for design of geopolymer concrete beams against shear and flexural failures. The load-deflection behaviour of eccentrically loaded slender geopolymer concrete columns can be calculated by using the same analytical approaches currently used for OPC concrete columns. These design approaches together with the Bresler's reciprocal formula can be used for conservative design of geopolymer concrete columns in axial compression and biaxial bending. Therefore, fly ash based geopolymer concrete can be used as a low-emission alternative to traditional OPC concrete for structural applications and the usual design practices can be used conservatively for design of geopolymer concrete structural members.

\section{References}

1. CEMBUREAU, The European Cement Association, Retrieved from http://www.cembureau.eu/ about-cement/key-facts-figures on 04 August, 2015.

2. Mehta, P.K., Reducing the Environmental Impact of Concrete, Concrete International, 23(6), 2001, pp. 61-66.

3. Sakai, K., Environmental Management of Concrete and Concrete Structures - Toward Sustainable Development in Construction Industry, Proceedings of the $6^{\text {th }}$ International Conference on Analytical Models and New Concepts in Concrete and Masonry Structures, Lodz, Poland, 9-11 June, 2008, pp. 139-155.

4. Chatterjee, A.K., Technological Initiatives and Status of Fly Ash in India, in Sarker, P.K. (ed.), Fly Ash: Sources Applications and Potential Environmental Impacts, Nova, USA, 2014, pp. 315-359.

5. Davidovits, J., Geopolymers: Inorganic Geopolymeric New Materials, Journal of Thermal Analysis, 37, 1991, pp. 1633-1656.

6. Rangan, B. V., Studies on Low-Calcium Fly Ashbased Geopolymer Concrete, Indian Concrete Institute Journal, October - December, 2006, pp. 9-17.

7. Fernandez-Jimenez, A.M., Palomo, A., and LopezHombrados, C., Engineering Properties of Alkaliactivated Fly Ash Concrete, ACI Materials Journal, 103(2), 2006, pp. 106-112.

8. Hardjito, D., Wallah, S.E., Sumajouw, D.M.J., and Rangan, B.V., On the Development of Fly Ash-based Geopolymer Concrete, ACI Materials Journal, 101(6), 2004, pp. 467-472.

9. Sofi, M., van Deventer, J.S.J., Mendis, P.A., and Lukey, G.C., Engineering Properties of Inorganic Polymer Concretes (IPCs), Cement and Concrete Research, 37, 2007, pp. 251-257.

10. Nath, P. and Sarker, P.K., Effect of GGBFS on Setting, Workability and Early Strength Properties of Fly Ash Geopolymer Concrete Cured in Ambient Condition, Construction and Building Materials, 66, 2014, pp. 163-171.

11. Nath, P. and Sarker, P.K., Use of OPC to Improve Setting and Early Strength Properties of Low Calcium Fly Ash Geopolymer Concrete Cured at Room Temperature, Cement and Concrete Composites, 55, 2015, pp. 205-214.

12. Nath, P. and Sarker, P.K., Geopolymer Concrete for Ambient Curing Condition, The Past, Present and Future of Structural Engineering, Proceedings of the Australasian Structural Engineering Conference, July 11-13, 2012, Perth, Western Australia. 
13. Sumajouw, D.M.J., Hardjito, D., Wallah, S.E., and Rangan, B.V., Flexural Behaviour Fly Ash Based Geopolymer Concrete Beams, Proceedings of the 22 $2^{\text {nd }}$ Bienniel concference of the Concrete Institute of Australia, Melbourne, Australia, 1619 October, 2005.

14. Hardjito, D. and Rangan, B.V., Development and Properties of Low Calcium Fly Ash-Based Geopolymer Concrete, Research Report GC1, Faculty of Engineering, Curtin University of Technology, (2005), available online at http://espace.lis. curtin.edu.au/.

15. ACI Committee 408, Bond Development of Straight Reinforcing Bars in Tension (ACI 408R03), American Concrete Institute, Farmington Hills, USA, 2003.

16. ASTM A 944-99, Standard Test Method for Comparing Bond Strength of Steel Reinforcing Bars to Concrete Beam-End Specimens, American Society for Testing and Materials Standard, West Conshohocken, US, 1999.

17. Sarker, P.K., Bond Strength of Reinforcing Steel Embedded in Geopolymer Concrete, Materials and Structures, 44, 2011, pp. 1021-1030.

18. Deb, P.S., Nath, P., and Sarker, P.K., The Effects of Ground Granulated Blast-furnace Slag Blending with Fly Ash and Activator Content on the Workability and Strength Properties of Geopolymer Concrete Cured at Ambient Temperature, Materials and Design, 62, 2014, pp. 32-39.

19. Chang, E.H., Sarker, P.K., Lloyd, N., and Rangan, B.V., Bond Behaviour of Reinforced Fly Ash Based Geopolymer Concrete Beams, Concrete Solutions 09, 24th Biennial Conference of the Concrete Institute of Australia, Sydney, 17-19 September, 2009.
20. Standards Australia, AS 3600-2009, Concrete Structures, 2009.

21. ACI Committee 318, Building Code Requirements for Structural Concrete, ACI 318-08, American Concrete Institute, Farmington Hills, MI, 2008.

22. Chang, E.H., Sarker, P.K., Lloyd, N., and Rangan, B.V., Shear Behaviour of Reinforced Fly Ash-Based Geopolymer Concrete Beams, Proceedings of the Concrete Institute of Australia 23rd Biennial Conference, Adelaide, Australia, October 18-20, 2007, pp. 679-687.

23. Sumajouw, D.M.J., Hardjito, D., Wallah, S.E., and Rangan, B.V., Fly Ash-Based Geopolymer Concrete: Study of Slender Columns, Journal of Materials Science, 42(9), 2007, pp. 3124-3130.

24. Sarker, P.K., Analysis of Geopolymer Concrete Columns, Materials and Structures, 42, 2009, pp. 715-724.

25. Rahman, M.M. and Sarker, P.K., Geopolymer Concrete Columns under Combined Axial Load and Biaxial Bending, Proceedings of the Concrete 2011 Conference, Oct 12-14, 2011, Perth, WA: The Concrete Institute of Australia.

26. Sarker, P.K., Adolphus, S., Patterson, S., and Rangan, B.V., High Strength Concrete Columns under Biaxial Bending, ACI Special Publication, 200, 2001, pp. 217-234.

27. Bresler, B., Design Criteria for Reinforced Columns under Axial Load and Biaxial Bending, ACI Journal, 57(5), 1960, pp. 481-490.

28. Rangan, B.V., High Performance High strength Concrete: Design Recommendations, Concrete International, 20(11), 1998, pp. 63-68. 